\title{
OBSERVED EFFECTS OF BODY MASS INDEX ON BLOOD PRESSURE DIPPING PATTERN, IN A PRIVATE HOSPITAL IN ABUJA, NIGERIA
}

\author{
*1Anya, O. C., ${ }^{2}$ Odugbemi, O., ${ }^{3}$ Okojie, E., ${ }^{4}$ Ayantayo, R. \& ${ }^{5}$ Ajayi, E.
}

${ }^{*}$ Department of Internal Medicine, Cardiocare Multispecialty Hospital, Abuja, Nigeria.

${ }^{2}$ Department of Emergency Medicine, Al-Sahan General Hospital, Kingdom of Saudi Arabia.

${ }^{3}$ Department of General Medicine, General Hospital Gbagada, Lagos, Nigeria.

${ }^{4}$ Department of Primary care, Nigeria Police Medical center, Akure, Nigeria.

${ }^{5}$ University of Alabama's Department of Internal Medicine Birmingham, Alabama. USA.

*Corresponding Author Email: o.anya@ limihospital.org_Phone: +2348039690456

\begin{abstract}
During a normal 24-hour ambulatory blood pressure monitoring (ABPM), there should be a more than 10\% drop in average nighttime blood pressure (BP), compared to the average daytime BP. This is called the normal ABPM dipping pattern. Abnormal dipping patterns occur when the average night-time blood pressure drop is lower than $10 \%$. A high body mass index has been described as a contributing factor for unusual ABPM dipping patterns, which predisposes an individual to a higher likelihood of developing cardiovascular disease. The goal of this research was to assess the link between the body mass index (BMI) and the dipping pattern during ABPM in the adult population who underwent ABPM at Cardiocare Abuja. Anthropometric data from 100 patients who had done ABPM were used, together with data obtained from the CONTEC ABPM50 device. The BMI was calculated with the weight and height, and they were grouped into weight classes using their BMI. The proportions of the various dipping patterns were then determined within each class. Majority of the participants involved in the study had BMI between 30-39 kg/m2. Those who presented with higher BMI classes were also discovered to have unusual dipping patterns, indicating a link with relation to the BMI and the ABPM dipping pattern. In the morbidly obese class, with BMI $>40$ $\mathrm{kg} / \mathrm{m} 2$ there was a trend of the reverse dipping. It concluded that ABPM should be done routinely for persons with a high BMI for early detection of unusual dipping patterns and prompt intervention.
\end{abstract}

Keywords: Ambulatory blood pressure monitoring, Body mass index, Non-dipping, Obesity, Reverse dipping

LICENSE: This work by Open Journals Nigeria is licensed and published under the Creative Commons Attribution License 4.0 International License, which permits unrestricted use, distribution, and reproduction in any medium, provided this article is duly cited.

COPYRIGHT: The Author(s) completely retain the copyright of this published article.

OPEN ACCESS: The Author(s) approves that this article remains permanently online in the open access (OA) model.

QA: This Article is published in line with "COPE (Committee on Publication Ethics) and PIE (Publication Integrity \& Ethics)". 


\section{INTRODUCTION}

Ambulatory blood pressure monitoring (ABPM) is used to maintain track of a person's blood pressure readings over the course of a 24-hour period of time. All through the day, while a person goes about their daily activities, their blood pressure values will change, and this chart will depict that fluctuation. ABPM was originally intended for use in clinical research, but recently it has gained popularity as a tool for diagnosing the four different blood pressure phenotypes, which include sustained normotension (normal in-office and at-home BP readings), white-coat hypertension (high in-office BP readings and normal at-home BP readings), masked hypertension (normal in-office $\mathrm{BP}$ readings and high at-home $\mathrm{BP}$ readings), and persistent hypertension (high in-office and at-home BP readings) (Cesare, et al., 2017).

When it comes to blood pressure, there is a significant diurnal fluctuation, with BP dropping to its lowest levels during nighttime sleep (Andrew, et al., 2002).

When blood pressure drops at night compared to daytime readings, this is considered a normal physiological process. It is attributed to sympathetic tone reduction and a parallel increase in vagal tone during sleep, and a drop in systolic and diastolic BP of more than $10 \%$ but less than $20 \%$ at night, in comparison to daytime readings, is known as the "normal dipping pattern" (Ingabire, et al., 2021). A decline of greater than $20 \%$ represents an "extreme dipping pattern", whereas a drop less than $10 \%$ represents a "non-dipping pattern". It is possible to have a reverse dipping trend if the nighttime BP readings are paradoxically elevated above the daytime measurements. ${ }^{3}$ The ABPM dipping pattern can be determined with the following equation: $100 \mathrm{x}$ (average daytime SBP - average night-time SBP) / (average daytime SBP - average night-time SBP) (average daytime SBP) (Shenzhen, et al., 2019).

"Patients with unusual ABPM parameters were postulated to have a more significant risk of stroke, according to O'Brien (1988), who initially described this". Many previous cross-sectional investigations in the general populace and hypertensive populations have showed that heart hypertrophy, silent cerebral infarction, and microalbuminuria are more prevalent among non-dippers compared to normal dippers (Yuichiro \& Kazuomi, 2012).

It was anticipated by Marwah et al, (2017), that by 2030 the number of obese and overweight persons would be 573 million and 1.35 billion, respectively, and it was also found in some studies that having a high BMI predisposed to abnormal ABPM dipping patterns (Vasilios, et al., 2005). According to one study, the influence of BMI on the 24hour ABPM parameters is minimal, and the factors that accounted for this variance were older age, different raceethnic compositions, and the use of anti-hypertensive medication (Baird, Zhezhen, Okajima \& Russo, 2018).

Understanding the manner in which a high BMI affects the "dipping pattern" during a 24-hour ABPM reading may be necessary to identify those who are at risk for the adverse effects of unusual dipping patterns and early intervention.

\section{MATERIALS AND METHODS}

Patients who presented to Cardiocare multispecialty hospital in Abuja, Nigeria for a 24-hour ABPM investigation between the $1^{\text {st }}$ of January 2020 and July 31st, 2021 had their demographics and anthropometry data and ABPM parameters obtained from their electronic medical records (EMRs). Cardiocare multispecialty hospital is the branch of the Limi Hospital group which specializes in cardiovascular medicine. In both hypertensive and non-hypertensive patients, ABPM is commonly done about four times a week in this facility. 
Hypertensive patients on medications were included in the study and majority were on anti-hypertensive medications such as "calcium-channel blockers", "beta blockers", "angiotensin-receptor blockers", and "angiotensin-converting enzyme inhibitors" regardless of medication efficacy. Non-hypertensive patients who experienced occasional elevated BP readings were also included. Initial selection for the experiment included 318 individuals, however this number was decreased to 100 excluding those with missing anthropometric data and total 24-hour ABPM readings less than 70.

Average reading was taken from four office readings done three minutes apart, two readings from each arm, and an OMRON HBP-1320-E with an appropriate-sized cuff was used for taking these readings. A CONTEC ABPM50 24-hour ABPM device was employed to get the 24-hour BP readings, and daytime measurements were programmed to read every 15 minutes while 30 minutes intervals were used for nighttime readings. Patients were usually advised to document sleeping and waking hours, and also to remain still when the device was taking a reading. After downloading data obtained from the device into the Cardiosoft Analysis Software, the "average daytime BP", “average nighttime BP”, "overall average 24-hour BP”, and characteristic "dipping patterns" were all automatically calculated by the software.

Following that, the 100 participants were classified into five categories based on their body mass indexes (BMIs). BMI less than $18 \mathrm{~kg} / \mathrm{m}^{2}$ was categorized as being in the 1 st class, BMI between 18 and $24 \mathrm{~kg} / \mathrm{m}^{2}$ was categorized as being in the 2nd class, BMI 25 to $29 \mathrm{~kg} / \mathrm{m}^{2}$ was categorized as being in the 3rd class, and BMI 30 to $39 \mathrm{~kg} / \mathrm{m}^{2}$ was categorized as being in the 4 th class. The morbidly obese, with BMI $>40 \mathrm{~kg} / \mathrm{m}^{2}$ were categorized as the 5th class.

The "dipping patterns" were also categorized into four; the "normal dipping pattern" (10-20\% drop in nighttime blood pressure readings), "non-dipping pattern" ( $<10 \%$ decrease in nighttime blood pressure readings), "extreme dipping pattern" ( $>20 \%$ drop in nighttime blood pressure readings), and the "reverse dipping pattern" $(>1 \%$ increase in nighttime blood pressure) were all identified. Data from each BMI class was analyzed with the SPSS program, version 1.0.0.1406 to discover the distribution of the various "blood pressure dipping patterns" within each BMI class. Ethical approval for the study was obtained from the Department of Medical Research Limi Hospital Abuja.

\section{RESULTS}

Hundred patients participated in the study; the average age was 43 years with an age range of 20 to 74 years. The male to female ratio was 57 to 43 . Forty-two patients had hypertension were being treated with antihypertensives such as 'calcium channel blockers', 'beta blockers', 'angiotensin-receptor blockers', and 'angiotensin-converting enzyme inhibitors', while 58 patients were normotensive but had occasional high blood pressure.

No patient presented in Class 1, 14 patients presented in Class 2 (14\%), 33 patients presented in Class 3 (33\%), 44 patients presented in Class 4 (44\%), and 9 patients presented in Class 5 (9\%). Table 1 displays the percentages of the different dipping patterns within the five BMI Classes, while Figure 1 depicts a diagrammatic representation of the proportion of the various dipping patterns among BMI Classes 2-5. In Class 2, there were 14 patients, 7 of whom had "normal dipping patterns" (50\%), 6 of whom had "non-dipping patterns" (43\%), and 1 who had an "extreme dipping pattern" (7\%). Class 3 with 33 patients, showed 9 patients with "normal dipping patterns" 
(27.3\%), 21 with "non-dipping patterns" (63.6\%), 2 with "extreme dipping patterns" (6.1\%), and 1with a "reverse dipping pattern" (3\%). When it came to Class 4 with 44 patients, only 19 of the 44 patients had "normal dipping patterns" (43.2\%), 20 had "non-dipping patterns" (45.4\%), and 5 had "reverse dipping patterns" (11.4\%). Class 5 with 9 patients had 3 "normal dipping patterns" (33.3\%), 3 "non-dipping patterns" (33.3\%), 2 "reverse dipping patterns" (22.2\%), and 1 "extreme dipping".

Table 1: Proportion of the different dipping patterns within the five BMI Classes.

\begin{tabular}{l|cccc}
$\begin{array}{l}\text { BMI Classes } \\
\left(\mathrm{kg} / \mathrm{m}^{2}\right)\end{array}$ & $\begin{array}{c}\text { Normal } \\
\text { Dipping (\%) }\end{array}$ & $\begin{array}{l}\text { Non-dipping } \\
(\%)\end{array}$ & $\begin{array}{c}\text { Reverse } \\
\text { Dipping (\%) }\end{array}$ & $\begin{array}{c}\text { Extreme } \\
\text { Dipping (\%) }\end{array}$ \\
$\begin{array}{l}\text { Class 1: } \\
<18\end{array}$ & 0.0 & 0.0 & 0.0 & 0.0 \\
$\begin{array}{l}\text { Class 2: } \\
\text { 18-24 }\end{array}$ & 50.0 & 43.0 & 0.0 & 7.0 \\
$\begin{array}{l}\text { Class 3: } \\
\text { 25-29 }\end{array}$ & 27.3 & 63.6 & 3 & 6.1 \\
$\begin{array}{l}\text { Class 4: } \\
30-39\end{array}$ & 43.2 & 45.4 & 11.4 & 0.0 \\
Class 5: & 33.3 & 33.3 & & \\
$>40$ & & & & \\
\hline
\end{tabular}

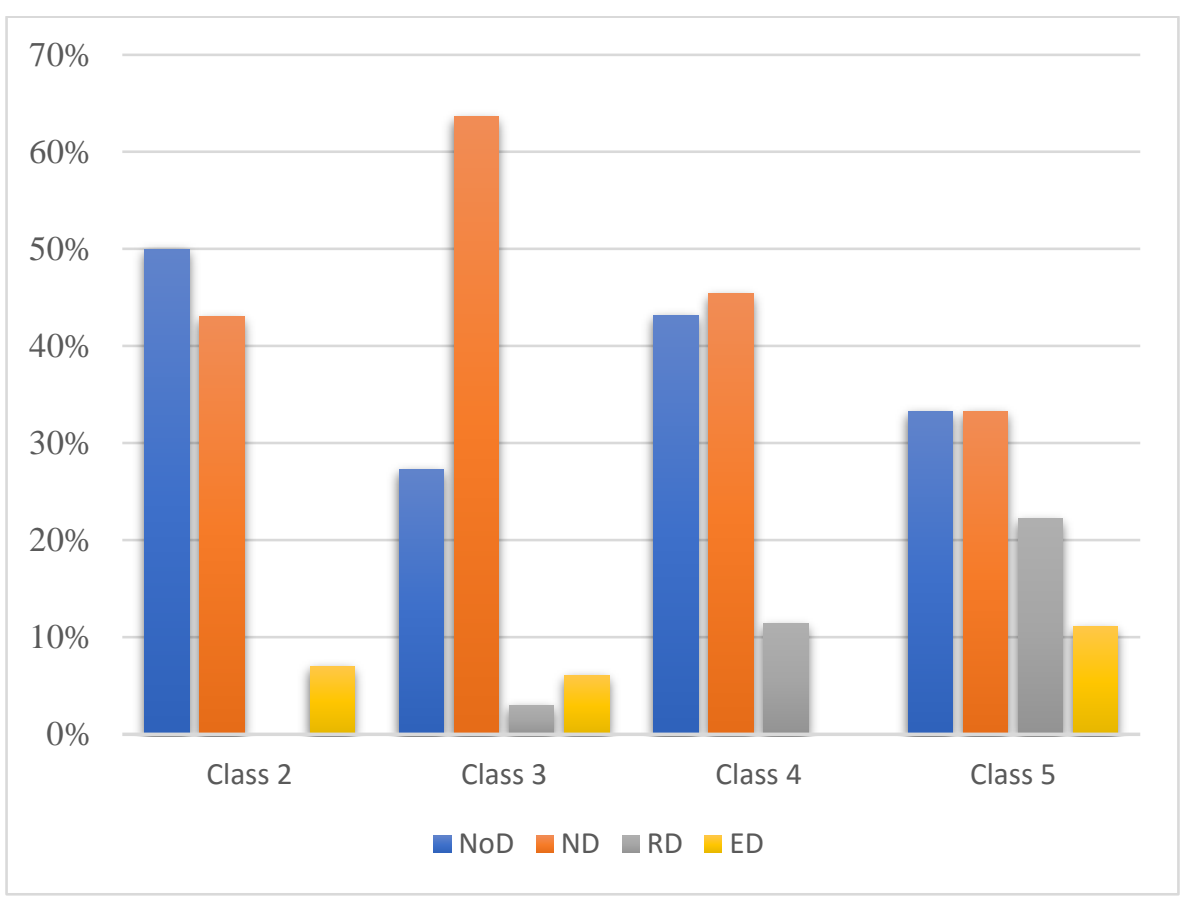

Figure 1: Bar graph representation of the proportion of the different dipping patterns in BMI classes 2-5. 


\section{DISCUSSION}

Study revealed that participants with a BMI between $30-39 \mathrm{~kg} / \mathrm{m}^{2}$ were most prevalent, constituting $44 \%$ of the total population. Those with a normal body mass index mostly had "normal dipping pattern", but with increasing BMI, the "non-dipping pattern" became higher than that of the "normal dipping pattern". In Class 3, with BMI 25-29 kg/m², the "non-dipping pattern" was noted to be the highest amongst all classes, and the first occurrence of the "reverse dipping pattern" was also observed in this class. The "reverse dipping pattern" steadily increased with increasing BMI from $3 \%$ in Class 3 with BMI $25-29 \mathrm{~kg} / \mathrm{m}^{2}$, to $11.4 \%$ in Class 4 with BMI $30-39 \mathrm{~kg} / \mathrm{m}^{2}$, and finally $22.2 \%$ in Class 5 with BMI $>40 \mathrm{~kg} / \mathrm{m}^{2}$. No "reverse dipping pattern" was seen amongst participants with a normal BMI. The "extreme dipping pattern" was seen amongst at patients except those who presented in Class 4 with BMI 30-39 kg/m².

A study was done to examine if an association existed between the BMI and both the 24-hour ABPM parameters and office blood pressure values. In the entire cohorts, regardless of age or gender, BMI and ABPM parameters were not associated. BMI and ABPM readings were minimally associated in people who weren't using antihypertensive medications, and no association existed between BMI and ABPM readings in known hypertensives on medications (Baird, Zhezhen, Okajima \& Russo, 2018). The dipping patterns of hypertensive patients on treatment and those not on treatment was not compared in the study.

A large study was done in Portugal by Araujo (2018), involving 26,170 24-hour ABPM readings with the aim to assess the blood pressure circadian patterns and their determinants in a large sample of normotensive and hypertensives individuals. It reported that individuals with a BMI of $30-39 \mathrm{~kg} / \mathrm{m}^{2}$ (obese population) and elderly subjects (>65 years) showed "non-dipping pattern" and the "reverse dipping pattern" significantly more frequently than the overweight (BMI 25-29 kg/m²) and normal (BMI 18-24 kg/m²) weight population. This aligns with part of the findings here which shows increased frequency of "reverse dipping pattern" in the Class 4, BMI 30-39 kg/m² and Class 5, BMI $<40 \mathrm{~kg} / \mathrm{m}^{2}$ groups, when compared to participants with a normal BMI (Class 2), and those in Class 3, with BMI $25-29 \mathrm{~kg} / \mathrm{m}^{2}$, but this study differed by finding a greater dominance of the "non-dipping pattern" in Class 3, BMI $25-29 \mathrm{~kg} / \mathrm{m}^{2}$ compared to Class 4, BMI $30-39 \mathrm{~kg} / \mathrm{m}^{2}$.

Another recent study with the aim to ascertain the blood pressure readings during an ABPM in obese patient with body mass index $>30 \mathrm{~kg} / \mathrm{m}^{2}$. A division was made amongst the participants into 2 groups, with Group 1 consisting of those with BMI $>30$ to $<40 \mathrm{~kg} / \mathrm{m}^{2}$ (equivalent to Class 4 here) and Group 2 consisting of those with BMI $>40 \mathrm{~kg} / \mathrm{m}^{2}$ (equivalent to Class 5 here). The percentage of nocturnal dipping was observed to be higher in group 1 as compared to group 2, while group 2 also had a higher proportion of the "reverse dipping pattern." (Moczulska, et al., 2020). No "extreme dipping pattern" was found in both groups unlike this study where an "extreme dipping pattern" was observed in Class 5 , BMI $>40 \mathrm{~kg} / \mathrm{m}^{2}$ (equivalent to Group 2).

The "non-dipping pattern" was discovered to be the most common unusual dipping pattern according to a local study which involved 120 Nigerians, while the "reverse dipping pattern" was seen to have the most risk for hypertension-mediated end-organ damage (Dele-Ojo, et al., 2021). Therefore, persons with a high BMI who will likely have an unusual 24-hour ABPM should undergo routine 24-hour ABPM for early detection of an abnormal dipping pattern, which provides an opportunity for early intervention. 


\section{LIMITATIONS OF THE STUDY}

The study had some limitations, including a sample size that may not have been large enough to delineate a defined association between the BMI and 24-hour ABPM dipping patterns. Secondly no individuals presented in Class 1 with a body mass index of $18 \mathrm{~kg} / \mathrm{m}^{2}$ or less, so no 24-hour ABPM parameters was seen in this class.

Finally, patient's co-morbidities like diabetes mellitus, renal issues, and endocrine diseases, and risk factors with adverse health effects such as alcohol use, smoking, high cholesterol, and so on, were not considered.

\section{CONCLUSION}

The body mass index and the 24-hour ABPM dipping pattern demonstrated a link, with patients with a high BMI having a larger percentage of unusual dipping pattern. These unusual dipping patterns raise the risk of medical disorders and so persons with a high BMI should routinely undergo ABPM for early detection risk and prompt intervention.

\section{CONFLICT-OF-INTEREST DISCLOSURE}

None

\section{ACKNOWLEDGEMENT}

Special thanks to Dr. Iseko Iseko and Dr. Awofisoye Oyindamola for all the encouragement, guidance and unrestricted access to hospital data. 


\section{REFERENCES}

Cesare, C., Carla, S., Tadic, M., Gherbesi, E., De Giorgi, A., Grassi, G., \& Mancia, G. (2017). Clinical and prognostic significance of a reverse dipping pattern on ambulatory monitoring: An updated review: Journal of Clinical Hypertension, 19 (7): 713-721.

Andrew, S., Patrick, R. S., Blumenthal, J., Kuhn, C., \& Hinderliter, A. (2002). Nighttime blood pressure dipping: the role of the sympathetic nervous system: American Journal of Hypertension, 15(2): 111-118.

Ingabire, P.M., Ojji, D.B., Rayner, B., Ogola, E., Damasceno, A., Jones, E., Dzudie, A., Ogah, O.,

Poulter,N., Sani, M., Barasa, F. A., Shedul, G., Mukisa, J., Mukunya, D., Wandera, B., Batte, C., Kayima, J., Pandie, S., \& Mondo, C. K. (2021). High prevalence of non-dipping patterns among Black Africans with uncontrolled hypertension: a secondary analysis of the CREOLE trial: BMC Cardiovascular Disorders 21, 254. https://doi.org/10.1186/s12872-021-02074-7.

Shenzhen, G., Kai, L., Runyu, Y., Li, J., Yang, C., \& Chen, X. (2019). Nocturnal dipping status and the association of morning blood pressure surge with subclinical target organ damage in untreated hypertensives: Journal of Clinical Hypertension, 21(9): 1286-1294.

O’Brien, E., Sheridan, J., \& O’Malley, K. (1988). Dippers and non-dippers: Lancet, ii.397.

Yuichiro, Y., \& Kazuomi, K. (2012). Nocturnal blood pressure and cardiovascular disease: a review of recent advances: Hypertension research, 35, 695-701.

Marwah, A., Caughey, M., Tanner, R. M., Booth $3^{\text {rd }}$, J. N., Diaz, K., Anstey, D. E., Sims, M., Ravenell, J., Muntner, P., Viera, A. J., \& Shimbo, D. (2017). Associations of Blood Pressure Dipping Patterns with Left Ventricular Mass and Left Ventricular Hypertrophy in Blacks: The Jackson Heart Study. Journal of the American Heart Association, 6 (4).

Vasilios, K., Stabouli, S., Marshall, B., Low, A., Toumanidis, S., \& Zakopoulos, N. (2005). Impact of obesity on 24Hour Ambulatory Blood Pressure and Hypertension: Hypertension, 45:602-602.

Stacy, W. B., Zhezhen, J., Okajima, K., \& Russo, C. (2018). Relationship between body mass and ambulatory blood pressure: comparison with office blood pressure measurement and effect of treatment: Journal of Human hypertension, 32 (2): 122-128.

Araujo, S., Rouxinol-Dias, A., Mesquita-Bastos, J., Silva, J., Barbosa, L., \& Polonia, J. (2018). Ambulatory blood pressure monitoring profiles in a cross-sectional analysis of a large database of normotensive and true or suspected hypertensive patients: Portuguese Journal of Cardiology, 37(4): 319-327.

Moczulska, B., Zechowicz, M., Lesniewska, S., Osowiecka, K., \& Gromadzinski, L. (2020). The impact of Obesity on Nighttime Blood Pressure Dipping: Medicinia (kaunas, Lithuania), 56(12): 700.

Dele-Ojo, B. F., Ogunmodede, J., Ojo, O. D., Katibi, I. A, Omotoso, A. B., Adeoye, M. A., \& Adesokan, A. (2021). Association between blood pressure dipping patterns and hypertension-mediated organ damage among Nigerians with newly-diagnosed hypertension: Research Journal of Health Sciences, 9(3). http://dx.doi.org/10.4314/rejhs.v9i3.1 